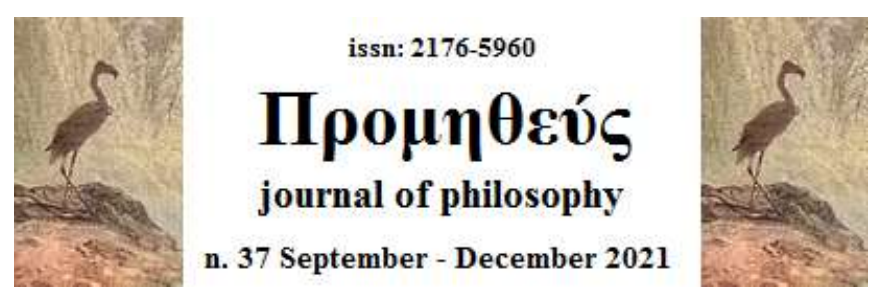

\title{
O SIGNIFICADO DA PAZ EM MAQUIAVEL: DESDE A GUERRA COMO SUA CONDIÇÃO DE POSSIBILIDADE ATÉ SEUS EFEITOS CÁUSTICOS
}

\author{
Douglas Antônio Fedel Zorzo \\ Doutor em Ética e Filosofia Política pela UNIOESTE
}

\begin{abstract}
RESUMO: O problema da "guerra", no pensamento de Nicolau Maquiavel, ocupa uma posição central e ininterrupta. O conjunto de sua teoria política, desde os textos clássicos até os escritos menores, é tomado e acompanhado pela iminência dos confrontos armados entre potências. Diante da imponência que as questões militares assumem em suas considerações, testemunhamos sua reflexão deslocar o significado que a paz, noção vinculada às implicações bélicas, assume. Nesse sentido, o presente artigo possui o propósito de avaliar o modo como o Secretário florentino compreende o período de tranquilidade entre estados. Isto é, como esse conceito se manifesta em suas obras, interagindo, diretamente, com o tópico da guerra. Para isso, por um lado, elucidaremos como o pensamento maquiaveliano apresenta a possibilidade, ainda que precária, de períodos pacíficos, ancorada em uma constante preparação para a guerra. E, por outro, delinearemos os efeitos cáusticos que emanam de um estado capaz de abdicar dos conflitos armados, onde o "ócio", oriundo do não engajamento militar, o transformaria em um corpo político "efeminado", visto como presa fácil pelas demais potências, ou "dividido", no qual floresce o germe para as guerras civis.
\end{abstract}

PALAVRAS-CHAVE: Maquiavel; guerra e política; guerra e paz.

ABSTRACT: In Niccolò Machiavelli's thought, the theme of "war" occupies a central and uninterrupted position. The whole of his political theory, from classical texts to minor writings, is crossed and accompanied by the imminence of armed confrontations between powers. Faced with the importance that military issues assume in those considerations, we witnessed his thinking shifting the meaning that peace, a notion linked to the warlike implications, assumes. In this sense, this article has the purpose of evaluating the way the secretary of the Florentine republic understands the period of tranquility between states. That is, how this concept manifests itself in his works, interacting directly with the topic of war. To achieve this, on the one hand, we will elucidate the way that Machiavellian thought presents the possibility, however precarious, of peaceful periods, anchored in a constant preparation for war. On the other hand, we will outline the caustic effects that affect a state capable of abdicating armed conflicts, where "idleness", arising from the lack of military engagement, would transform it into an "effeminate" political body, seen as easy prey by other powers, or "divided", where the germ for civil wars flourishes.

KEYWORDS: Machiavelli; war and politics; war and peace. 


\section{Introdução}

A questão da "guerra" ocupa uma posição central tanto na biografia quanto na economia do pensamento político, literário e historiográfico de Nicolau Maquiavel. Esse conceito, sempre recorrente, atravessa sua biobibliografia. No conjunto de suas obras, os conflitos, em suas diversas configurações e manifestações, são tópicos recorrentes e regulares ${ }^{1}$. Ali, a política aparece envolta por uma contínua presença e ameaça da guerra, o que impacta, de maneira profunda, as atividades de governo. Ao invés de uma mera eventualidade, os confrontos armados despontam como um risco concreto e irrevogável, que constantemente colocam em perigo a conservação de estados e a existência de regimes políticos.

De fato, para o Secretário florentino, esse fenômeno surge como um evento natural e ordinário na dinâmica "internacional"2. Considerando o grave panorama político das relações entre as potências que formavam a precária colcha de retalhos institucional da Europa do Cinquecento $^{3}$, marcada por uma conjuntura de luta

1 Podemos notar que o pensamento do Secretário sobre a guerra é desenvolvido de maneira ininterrupta. Partindo da constatação da importância das atividades armadas no interior da prática política, presente já em seus primeiros escritos, redigidos ainda a cargo da Segunda Chancelaria de Florença, onde atuou como o principal defensor, idealizador e executor do ousado projeto de formação de uma milícia própria para a cidade; passando pela presença da violência nos episódios de formação dos regimes principescos, no reconhecimento da indispensabilidade dos exércitos na manutenção desses governos, e tocando na desconcertante avaliação das condições militares das cidades italianas no período, em $O$ Príncipe; estabelecendo um apurado estudo sobre as organizações políticoinstitucionais, táticas e estratégicas de Roma e de sua milícia republicana, nos Discursos sobre a primeira década de Tito Lívio; até chegar à formulação de uma proposta de exército próprio, fruto desse acúmulo de experiência pessoal e análise "intelectual”, em a Arte da Guerra.

${ }^{2}$ Como escreve Maquiavel para Francesco Guicciardini em uma carta de 3 de janeiro de 1525, " [...] sempre, desde que tenho recordação, ou se fez guerra ou se pensou em fazê-la. Logo se fará, e quando terminar, se pensará novamente em fazê-la, de modo que não se terá tempo de pensar em mais nada" (MACHIAVELLI, 1999, p. 416, tradução nossa).

${ }^{3}$ De um lado, as grandes potências europeias, como a Espanha, e, sobretudo, a França e o Sacro Império Romano-Germânico, que amiúde davam provas de sua imponência militar. De outro, os frágeis estados italianos, politicamente instáveis, dependentes de delicadas alianças, débeis, carentes de estruturas militares, e, por isso, transformados em campos de batalha para estrangeiros. 
ininterrupta, a atenção à tal temática se consolidará com um aspecto robusto no horizonte maquiaveliano.

Todavia, essa forma de compreensão sobre a guerra está estruturalmente vinculada à noção de paz. Na verdade, diante da centralidade e a imponência que o problema bélico assume em Maquiavel, testemunhamos seu pensamento político-militar deslocar o significado que o período de tranquilidade entre domínios territoriais distintos possui. É justamente aqui que nosso esforço pretende se inserir. Assim, o presente artigo tem por intuito avaliar a percepção teórica do Secretário sobre a paz. Isto é, analisar como esse conceito, enquanto elemento que interage com o tópico da guerra, se manifesta no pensamento maquiaveliano. Para ponderarmos sobre os termos da relação desse binômio, nos guiaremos por dois caminhos. Por um lado, examinaremos as condições de possibilidade para a "concórdia" na arena entre estados, algo que se manifestará atrelado à capacidade e à disposição dos estados para os conflitos armados. Por outro, elucidaremos os riscos cáusticos que uma situação de paz plena comporta, sendo responsável por corroer as estruturas políticas dos estados através do grassar do ócio.

\section{A pressuposição da guerra como condição de possibilidade para a paz}

$\mathrm{Na}$ teoria maquiaveliana, a guerra é compreendida como uma possibilidade permanente $^{4}$. A partir dessa percepção, que constitui a pedra angular de todo o seu pensamento político-militar, a paz não pode remeter à simples ausência de confrontos armados. Antes disso, essa noção passa a ser entendida como um momento de preparação, de prelúdio, para a guerra. Isto é, a tranquilidade "interestatal” deixa de ser apreendida como uma situação regular e estável, uma propriedade natural do vivere civile que seria perturbada por eventuais acontecimentos beligerantes. Ao contrário, a paz revela-se como uma circunstância específica, propiciada pela atenção que é

\footnotetext{
${ }^{4}$ Sobre a importância que a guerra assume no corpus maquiaveliano, Felix Gilbert (1977, p. 254, tradução nossa), por exemplo, afirma que "todo o pensamento político de Maquiavel gravita inevitavelmente em torno da indagação sobre a função do poder militar na vida política". No final, enfatiza o intérprete, a "arte da guerra" era não apenas seu "argumento favorito" (GILBERT, 1977, p. 197), como acabou se tornando "a atividade mais importante da vida política" (GILBERT, 1986, p. 24, tradução nossa). Sydney Anglo (1988, p. 321, tradução e grifo nossos), por seu turno, sustenta que a importância da guerra era algo "óbvio" para Maquiavel. A "organização militar, a virtù militar e os perigos decorrentes da incapacidade militar foram suas preocupações constantes", de modo que "a guerra preenche seus livros e constitui o núcleo de seu pensamento político".
} 
dedicada à guerra. Nisso, a organização e a disposição militar durante os períodos de não agressão são os elementos que a promovem.

Essa característica aparece, pontual, no capítulo XIV de O Príncipe, onde podemos notar com clareza os termos através dos quais o Secretário concebe a matéria. Em um tom insuflado, motivado, sobretudo, pela caótica situação "geopolítica" italiana, afirma que um príncipe deve "não ter outro objetivo, nem pensamento, nem tomar como arte sua coisa alguma que não seja a guerra, sua ordem e disciplina, porque esta é a única arte que compete a quem comanda". Com efeito, "é de tanta virtù" ser versado nos assuntos militares que isso "não só mantém aqueles que já nasceram príncipes, como também muitas vezes permite que homens de condição privada ascendam ao principado". Ao invés disso, "vê-se que os príncipes que pensam mais em refinamento [alle delicatezze] do que nas armas perdem o seu estado [hanno perso lo stato loro]". O motivo que "te leva a perder teu estado é negligenciar essa arte, e a razão que te faz conquistá-lo" é "essere professo di questa arte" (MAQUIAVEL, 1998, p. 69). Logo, "um príncipe não deve jamais afastar o pensamento do exercício da guerra e, durante a paz, deve praticá-la ainda mais do que durante a guerra" (MAQUIAVEL, 1998, p. 70, grifo nosso).

Será sobre esse movimento, que, além de alertar, substancializa a importância da não desconsideração pelas atividades militares durante os períodos de calmaria, que Maquiavel irá edificar uma severa crítica contra os governantes italianos do Cinquecento. Ora, no encerramento de a Arte da Guerra lemos que "os nossos príncipes [principi]" acreditavam, "antes de experimentarem os golpes das guerras ultramontanas", isto é, da incursão de Carlos VIII, rei da França, em 1494, responsável por convulsionar as estruturas e as relações políticas dos estados da península, que, "a um príncipe", era suficiente

[...] estar no gabinete a encontrar respostas agudas, escrever belas cartas, mostrar argúcia e sagacidade em ditos e frases, urdir fraudes, ornar-se de gemas e ouro, dormir e comer com mais esplendor que os outros, comportar-se com ganância e soberba diante dos súditos, apodrecer [marcirsi] no ócio, conceder graus militares de graça, desprezar quem lhes mostre alguma saída louvável, querer que suas palavras sejam respostas de oráculos (MAQUIAVEL, 2006, p. 223).

Contudo, "nem desconfiavam, os coitados [meschini], que se preparavam para ser presa de qualquer um que os atacasse". Essa foi, prossegue o Secretário, a "origem 
dos grandes sustos, das súbitas fugas e das miraculosas perdas", já que "três poderosíssimos estados que pertenciam à Itália”, Milão, Veneza e Florença, “foram várias vezes saqueados e devastados"

Lamentavelmente, os governantes remanescentes "incidem no mesmo erro e vivem na mesma desordem" (MAQUIAVEL, 2006, p. 223). Essa negligência com a preparação dos mecanismos bélicos, ou, ainda, essa compreensão equivocada de sua dinâmica durante os irregulares lapsos de paz, constituía uma importante causa para a ruína dos estados italianos, que, desarmados, se encontravam acuados pelas potências estrangeiras.

O entendimento da guerra como instrumento de viabilidade para a paz apareceria, de maneira mais incisiva, no Capítulo 19 do Livro I dos Discursos sobre a primeira década de Tito Lívio ${ }^{6}$. Nessa instância, essa reflexão se encontra subjacente a uma análise que Maquiavel conduz, perscrutando a história romana e o comportamento de alguns de seus governantes, acerca do argumento de que "depois de um príncipe excelente pode-se manter um príncipe fraco; mas, depois de um fraco, não se pode manter reino algum com outro príncipe fraco".

Para isso, afirma o Secretário, é conveniente considerarmos a "virtù e o modo de proceder" dos três primeiros reis romanos, Rômulo, Numa e Tulo Hostílio, onde veremos que Roma "foi sorteada com uma fortuna imensa", pois o primeiro rei foi "ferocíssimo e belicoso, enquanto o segundo foi tranquilo e religioso, ao passo que o terceiro se assemelhou em ferocidade a Rômulo, sendo mais amante da guerra que da paz" (MAQUIAVEL, 2007a, p. 76, grifo nosso).

Diante do propósito da investigação maquiaveliana e das qualidades particulares desses três governantes, "era necessário que nos primórdios de Roma surgisse um ordenador da vida civil", e que, depois, "outros reis retomassem a virtù de Rômulo": "se isso não ocorresse a cidade se tornaria efeminada e presa fácil dos vizinhos". A conclusão que emana desse quadro é a da que "um sucessor que não tenha tanta virtù

\footnotetext{
${ }^{5}$ Como ratifica Maquiavel no Capítulo XXIV de O Príncipe (MAQUIAVEL, 1998, p. 117): “[...] considerando aqueles senhores que, na Itália, em nossos tempos, perderam seus estados [...] encontraremos neles, primeiro, um erro comum quanto aos exércitos". Consequência que não é surpreendente, já que "aquele que despreza" os pensamentos sobre a guerra, "se for príncipe, estará desprezando o seu principado; se for cidadão, a sua cidade” (MAQUIAVEL, 2006, p. 225).

${ }^{6}$ Doravante, nos referiremos a esse escrito apenas como "Discursos".
} 
quanto o primeiro pode manter um estado graças à virtù daquele que o governou antes, sendo possível gozar os frutos de seu trabalho", porém, "se ocorrer que sua vida seja longa ou que depois dele não surja outro que retome a virtù do primeiro, é necessário que tal reino se arruíne” (MAQUIAVEL, 2007a, p. 77, grifo nosso).

A "fraqueza", portanto, do rei intermitente entre Rômulo, "ferocíssimo e belicoso", e Tulo Hostílio, "amante da guerra", Numa ${ }^{7}$, "tranquilo e religioso", é rearranjada sob o signo da desconsideração crucial pelas atividades militares. Um estado que, pela ação da fortuna, seja capaz de oscilar entre os termos de guerra e paz poderia conservar-se por um longo período, porque o trabalho de um governante belicoso é desfrutado por outro amante da paz, como em Roma. Entretanto, a sucessão não é garantida. Outra vez, a excelência nas armas se torna o ensejo para essa "concórdia", que havia sido propiciada pelo engenho de um ordenador político-militar pregresso, mas que, agora, se encontra fragilizada pelo atual estado de inércia dos governantes.

A paz, desse modo, é momentaneamente possível por ser consequência do amplo envolvimento do governo anterior nas coisas da guerra. Dessa situação, conclui Maquiavel, "quero [...] dizer [...] que, depois de um príncipe excelente, um príncipe fraco pode manter-se", mas "depois de um príncipe fraco, nenhum reino pode manter-se com outro príncipe fraco": "e são fracos os príncipes que não se ocupam da guerra" (MAQUIAVEL, 2007a, p. 78).

O caso de Roma, nessa ocasião, é paradigmático. Se “a virtù de Rômulo foi tão grande que deu a Numa Pompílio a possibilidade de governar Roma durante muitos anos com a arte da paz", depois dele, veio "Tulo, que com sua ferocidade recuperou a fama de Rômulo". Em seguida, "veio Anco, dotado pela natureza de tal modo que podia usar a paz e suportar a guerra". Aliás, "começou por desejar manter a vida da paz, mas logo percebeu que os vizinhos, considerando-o efeminado, o menosprezavam, e assim achou que, para manter Roma, precisava voltar-se para a guerra" (MAQUIAVEL, 2007a, p. 78). Então, uma cidade "bem ordenada", sentencia Maquiavel, é aquela que

\footnotetext{
7 Apesar disso, Maquiavel reconhece que Numa realizou outras ações que contribuíram para a estruturação da força militar romana, como a organização religiosa. Acerca da eleição de Numa para o Senado, afirma Capítulo 11 do Livro I dos Discursos, que "[...] julgando que as ordenações de Rômulo não bastavam a tanto império, inspiraram no peito do Senado romano a eleição de Numa Pompílio como sucessor de Rômulo, para que as coisas que Rômulo deixara sem fazer fossem ordenadas por Numa; este, encontrando um povo indômito e desejando conduzi-lo à obediência civil com as artes da paz, voltou-se para a religião, como coisa de todo necessária para se manter uma cidade [civiltà]]" (MAQUIAVEL, 2007a, p. 48-49, grifo nosso).
} 
“em tempos de paz não negligencia as ordenações da guerra" (MAQUIAVEL, 2007a, p. $80)$.

Uma ideia de teor de semelhante já havia sido encubada durante o exercício de suas atividades no interior da Segunda Chancelaria. Nas Parole da dirle sopra la provisione del danaio, facto un poco di proemio e di scusa ${ }^{8}$, por exemplo, após expor, através de uma argumentação colorida por tonalidades alarmantes, a pertinência da força para a conservação das estruturas políticas de Florença, o Secretário explicava que "toda cidade, todo estado [ogni città, ogni stato], deve reputar como inimigos [inimici] todos aqueles que possam tratar de ocupá-lo e aqueles contra os quais não pode se defender". De fato, “jamais existiram nem um Senhor nem uma República sensatos que quiseram manter seu estado à mercê dos outros [tenere lo stato suo ad discretione d'altri], ou que mantendo-o acreditassem havê-lo seguro" (MACHIAVELLI, 1997, p. 13, tradução nossa). Se, por um lado, “entre os homens privados são as leis, os escritos e os pactos o que fazem observar a fé [dada]", por outro, "entre os senhores somente as armas a mantém" (MACHIAVELLI, 1997, p. 14, grifo nosso) $)^{9}$.

Enquanto a dinâmica entre indivíduos privados, que vivem sob um mesmo domínio, é pautada por uma violência subsumida na coação da lei, que obriga ao cumprimento dos acordos, entre os organismos políticos isso só é plausível através do recurso à uma violência que se apresenta de forma mais crua, ou seja, por meio dos

\footnotetext{
${ }^{8}$ Escrito redigido em março de 1503 para ser pronunciado por alguém notório, talvez por Piero Soderini, gonfaloneiro vitalício de Florença, em alguma assembleia (nas Consulte, no Consiglio degli Ottanta ou no Consiglio Maggiore) para ressaltar a delicada situação em que Florença se encontrava: debilitada financeira e militarmente e, por causa disso, exposta diante das ameaças que Cesare Borgia, personagem central de $O$ Príncipe, lançava sobre a república. A situação era agravada pois as várias Consulte e o próprio Consiglio Maggiore protelavam a votação dos impostos que deveriam remediar essa situação. Exatamente para persuadir sobre a necessidade de tomar uma decisão que essas "parole" deveriam ser pronunciadas.

${ }^{9}$ A mesma constatação da força como via de factibilidade para as relações "internacionais" aparece na Seconda Legazione al Valentino, onde o Secretário acompanha o desenrolar das ações de Cesare Borgia, aquilatando seu impacto para Florença. Em uma correspondência de 8 de novembro de 1502, remetida aos Dieci, Maquiavel ponderava que, segundo sua opinião ("parlando sempre come da me"), a "excelência desse duque - Cesare Borgia - não poderia ser medida como a de outros Senhores", devendo-se considerá-lo como "um novo potentado na Itália, com o que é melhor fazer uma liga e amizade, ao invés de uma condotta". Entretanto, "as amizades entre os Senhores são mantidas somente com as armas" (MACHIAVELLI, 1999, p. 701). A mesma lição ressurgiria na História de Florença quando Maquiavel relatava a devolução dos castelos florentinos, por parte do rei de Nápoles, que o duque da Calábria havia tomado em sua tentativa de assenhorear-se de Siena. O rei de Nápoles, então em guerra contra os turcos, "temia que os florentinos o abandonassem num momento de tanta necessidade". Dessa forma, "assentiu em restituí-los e, com novos favores, obrigou de novo os florentinos a favorecê-lo". Disso, extrai que "é pela força e pela necessidade, e não por documentos e obrigações [scritture e gli oblighi], que os príncipes cumprem a palavra dada" (MAQUIAVEL, 2007b, p. 528).
} 
exércitos. Por certo, conforme argumenta Jean-Jacques Marchand (1975, p. 326, tradução nossa), entre "duas nações, que são amigas ou inimigas", apenas "o mútuo respeito devido à potência militar pode permitir uma colaboração profícua" ou uma “coexistência relativamente pacífica". Nessa mesma esteira, Fabio Frosini (2004, p. 17, tradução nossa), por sua vez, pondera que a disponibilidade para a guerra "é o único modo para conferir validade aos pactos" firmados, bem como para "estabelecer as condições de amizade" entre os estados. Em geral, "a paz é fundada sobre a guerra" bem como "a amizade é fundada sobre a igualdade", e, no "terreno da política internacional”, "a única igualdade possível é a igual potência bélica". Enfim, conclui o intérprete, "paz, pactos e política possuem uma consistência própria, uma esfera de existência, que tornam-se realmente pensáveis se são reconduzidas à guerra como sua condição de possibilidade" 10 .

De certa forma, sobre essa questão, o pensamento maquiaveliano parece ter absorvido e desdobrado a célebre sentença latina que postulava o "si vis pacem, para bellum". Segundo a leitura costumeira desse adágio, a garantia para a paz de um estado residia em seu armamento e na preparação das condições de sua defesa pelas vias armadas. Embora de origem anônima, essa ideia ecoava, sob diversas formulações, em autores com os quais o Secretário havia tido contato direto ou indireto.

No Epitoma rei militaris, de Publio Flavio Vegezio, por exemplo, que teria servido como guia para a escritura do diálogo d'Arte da Guerra de Maquiavel ${ }^{11}$, lemos que "quem aspira à paz, deve preparar-se para a guerra [qui desiderat pacem, praeparet bellum]". Isto é, "quem deseja a vitória, [que] treine diligentemente os soldados", pois "quem pretende eventos favoráveis, combate com arte e não ao acaso" (VEGEZIO, 1984, p. 80, tradução nossa). Essa mesma premissa por ser identificada na Settima Filippica de Cícero, onde o orador romano sustenta que "[...] não é a paz que eu refuto, mas é uma guerra escondida sob o nome de paz que eu tenho um grande medo". Por consequência, "se queremos gozar da paz, é necessário fazer a guerra [si pace frui

\footnotetext{
${ }^{10}$ Frosini retoma, ainda que en passant, essas considerações em sua obra Maquiavel: o revolucionário (Tradução de Ephraim Ferreira Alves. São Paulo: Ideias \& Letras, 2016). Sobre isso, cf., especialmente, o capítulo III, "Guerra e Política entre O Príncipe e os Discursos" (p. 103-128).

11 Essa tese é apresentada, por exemplo, por Arthur Burd em Le fonti letterarie di Machiavelli nell'Arte della Guerra (Atti della Academia dei Lincei, v. 5, n. 4, p. 187-261, 1896). Sobre a relação entre Maquiavel e Vegezio, cf. de Marco Formisano, Strategie da manuale: l'arte della guerra, Vegezio e Machiavelli (Quaderni di Storia, v. 55, p. 99-127, 2002).
} 
volumus, bellum gerendum est]; se interrompermos a guerra, não gozaremos nunca da paz” (CICERONE, 1978, p. 451-453, tradução nossa) ${ }^{12}$.

Independentemente da inspiração, ou de uma certa filiação intelectual de Maquiavel, essa visão sobre a paz não designa um mundo no qual a violência reine incessante. Representa, ao contrário, uma relação entre ordens estatais de poder que, no controle ordinário do território e da zona de influência que é indispensável para sua subsistência, não pode deixar de recorrer à preparação dos exércitos para a constituição de uma potência ofensiva ou defensiva.

Em outras palavras, como sintetiza Luigi Zanzi (2009, p. 94, tradução nossa), a "capacidade de fazer guerra" é reconhecida como um dos recursos vitais do estado, inclusive daqueles cujo propósito é manter eficazmente uma ordenação de paz. Assim, reforçam Jean-Louis Fournel e Jean-Claude Zancarini (2015, p. 678, tradução nossa), a paz pode ser procurada, "mas é necessário saber que a guerra é mais do que provável, e talvez também necessária para obter a paz". Guerra e paz funcionam como um "binômio no qual os dois termos são indissociáveis, cada um dos dois sendo útil para pensar o outro", mesmo porque a "qualidade dos tempos" faz com que "se possa passar rapidamente de uma situação para outra”.

Com isso, Maquiavel nos arrasta para uma direção um tanto desconfortável. A paz não apenas passa a ser concebível quando vista como um equilíbrio transitório entre forças que estão sempre prontas para a guerra, mas, ela própria, surge como potencialmente nociva aos corpos políticos, uma vez que cria uma imagem enganosa de que as guerras possam ter encontrado um desfecho permanente ${ }^{13}$. Isso alastra a inércia militar pelo estado, paralisando a reação diante de uma agressão. Quando a conjuntura política externa, sempre volátil e instável, se altera, a mesma imobilidade revela-se fatal. Nesse caso, se os conflitos armados surgem sob a sombra do inevitável, não é a guerra que deve ser considerada como algo prejudicial ou implicitamente maligno, mas as ações que, durante sua ausência, desconsideram a iminência de seu [res]surgimento.

\footnotetext{
${ }^{12}$ Recuperamos a mesma afirmação em Cornelio Nepote, contemporâneo a Cícero: “A paz nasce da guerra [nam paritur pax bello]: quem dessa deseja gozar longamente deve manter-se em exercício para a guerra" (NEPOTE, 1977, p. 212-213, tradução nossa).

${ }^{13}$ Bem como os cidadãos florentinos que, "quando veem o sol, não acreditam nunca que possa voltar a chover” (MACHIAVELLI, 1997, p. 15-16).
} 


\section{Da tranquilidade à ruína: os efeitos cáusticos da paz}

No entanto, embora o tópico pregresso tenha possibilitado a formação de uma imagem rudimentar sobre a paz no pensamento de Maquiavel, a "tranquilidade" no cenário "internacional" comporta ainda uma consequência mais profunda. Para o Secretário, uma suposta "harmonia" é responsável por introduzir, nos corpos políticos, um elemento que opera como germe da corrupção e como preâmbulo para a ruína: o "ócio".

Entendido como decorrência da falta de engajamento militar, o ozio fragiliza os estados tanto sob uma perspectiva externa de vulnerabilidade à conquista estrangeira com a qual estamos familiarizados -, quanto interna, como o motivo para o dilaceramento da "coesão" civil. Isto é, as cidades que encontram meios para abdicar de seus conflitos, e que, por isso, passam incólumes a um contexto obstinado de guerras, encontrar-se-ão duplamente expostas.

Sobre a ação cáustica do ócio, Maquiavel, no Capítulo 1 do Livro V da História de Florença, afirmava que "as províncias, na maioria das mudanças que sofrem, costumam sair da ordem e entrar na desordem, para depois passarem de novo da desordem à ordem. Pois, "não permitindo a natureza humana que as coisas mundanas tenham parada, quando elas chegam à sua máxima perfeição, não podendo subir mais, é mister que desçam". Ainda que, "depois de descer, haverão necessariamente de subir". Esse quadro que alterna a ascensão e o declínio dos estados é oriundo do fato de que

[...] a virtù gera a tranquilidade, a tranquilidade gera o ócio; o ócio, a desordem, e a desordem, ruína; de modo semelhante, da ruína nasce a ordem; da ordem, a virtù, desta, a glória e a boa fortuna" (MAQUIAVEL, 2007b, p. 281).

Nesse sentido, encontramos uma consideração semelhante nos tercetos do Capítulo $\mathrm{V}$ do poema L'Asino, onde o Secretário pondera que

\footnotetext{
A virtù torna as regiões tranquilas:

e da tranquilidade emerge

o ócio: e o ócio destrói as cidades e as vilas.

Então, após uma província estar envolvida

por muito na desordem,
} 
a virtù volta a habitá-la.

Essa ordem é imposta e exigida àqueles que governam, até que nada esteja ou possa estar firme sob o Sol.

(MACHIAVELLI, 1971, p. 967, tradução nossa).

Aqui, por implicação lógica, devemos nos perguntar: de que forma o "ócio", subproduto, ou resultado, da paz e da tranquilidade, poderia representar um perigo para o estado, ao ponto de propiciar seu ocaso? Ou melhor, quais seriam os elementos de "corruptibilidade", por ele introduzidos, que solapam as instituições e as ordenações civis?

A resposta para essas interrogações pode ser encontrada no encerramento da reflexão do Capítulo 6 do Livro I dos Discursos. Na sequência de uma intrincada e controversa argumentação, iniciada no Capítulo 4, que tinha como epicentro a temática dos tumultos entre "grandes" e "povo" e a tese acerca dos efeitos benéficos do entrechoque de seus desejos ${ }^{14}$, Maquiavel chegava até a comparação entre dois modelos republicanos distintos. De um lado, Roma, de tendência popular, uma potência militar que havia feito da expansão territorial um importante instrumento político. De outro, Esparta e Veneza, de matriz aristocrática, repúblicas às quais havia bastado a conservação de seus domínios, dispensando a formação de grandes exércitos.

Após desconstruir metodicamente a pertinência dos estados conservacionistas, que, em um contexto de guerra constante, ignoravam a necessidade da formação de estruturas militares expressivas - pois, para evitar os tumultos internos, mantinham o povo alheio às instituições políticas e, consequentemente, não podiam se servir dessa

\footnotetext{
${ }^{14}$ Argumento que tem despertado a atenção de uma vasta e variada rede de intérpretes do pensamento maquiaveliano. Sobre isso, cf., por exemplo, ESPOSITO, R. Ordine e conflitto: Machiavelli e la letteratura politica del Rinascimento italiano (Napoli: Liguori Editore, 1990); CADONI, G. Crisi della mediazione politica e conflitti sociali (Roma: Jouvence, 1994); SFEZ, G. Machiavel, la politique du moindre mal (Paris: Presses Universitaires de France, 1999); GAILLE, M. Conflit civil et liberté: la politique machiavélienne entre histoire et médecine (Paris: Honoré Champion, 2004); AUDIER, S. Machiavel, conflit et liberté (Paris: Vrin/Ehess, 2005); GEUNA, M. Machiavelli ed il ruolo dei conflitti nella vita politica (In: ARIENZO, A.; CARUSO, D. (Ed.). Conflitti. Napoli: Libreria Dante \& Descartes, 2005. p. 19-57). No cenário nacional, que dialoga com essas vertentes, podemos citar, ADVERSE, H. Maquiavel, a república e o desejo de liberdade (Trans/Form/Ação, v. 30, n. 2, , p. 3352, 2007; AMES, J. L. Liberdade e conflito: o confronto dos desejos como fundamento da ideia de liberdade em Maquiavel (Kriterion, v. 119, p. 179-196, 2009), e, mais recentemente, Conflito e liberdade: a vida política para Maquiavel (Curitiba: Editora CRV, 2017).
} 
categoria de indivíduos nos exércitos ${ }^{15}$-, o Secretário retornava ao problema da paz. Imerso em um discurso hipotético, afirma que, ainda que a guerra pudesse ser evitada, e o "Céu" fosse "tão benévolo" ao ponto de não obrigar uma cidade a "guerrear, o ócio a tornaria efeminada ou dividida; coisas que, juntas, ou cada uma por si, seriam a razão para sua ruína” (MAQUIAVEL, 2007a, p. 32).

O ócio, então, debilita o corpo político tanto sob a perspectiva externa, ao tornálo efeminado, quanto pela perspectiva interna, ao segmentá-lo por divisões e abrir uma brecha para as guerras civis. Estamos diante de duas causas para a ruína que, de forma autônoma ou em ação conjunta, determinam seu colapso. Mas, em termos específicos, o que significa uma cidade que se torna effeminata ou divisa?

Por um lado, recorrendo à uma terminologia depreciativa ${ }^{16}$, que opõe-se à ferocidade e à dureza ${ }^{17}$, um estado efeminado é aquele que, ao sucumbir ao ócio, é enfraquecido e considerado como frívolo. Em outras palavras, essa fragilidade é causada pela ausência de uma potência de guerra, o que faz com que a organização política seja vista como presa fácil para a conquista estrangeira.

15 Em resumo, na ocasião Maquiavel alertava que aos ordenadores que, caso desejassem que a república se expandisse, deveriam "dar lugar da melhor maneira possível a tumultos e a dissensões entre cidadãos", pois "sem grande número de homens bem armados, nunca república alguma poderá ampliar-se, e, caso se amplie, não poderá manter-se" (MAQUIAVEL, 2007a, p. 30). Isso decorre do fato de que "se queres [tu vuoi] criar um povo numeroso e armado para poderes criar um grande império, acabarás por fazê-lo de tal maneira que não poderás depois manejá-lo [maneggiare] a teu modo" (MAQUIAVEL, 2007a, p. 30). Seria necessário, assim, procurar a institucionalização dos tumultos, por meio da concessão de prerrogativas políticas ao povo. Para ordenar uma república à qual baste se manter, como Esparta e Veneza, seria preciso manter o povo "pequeno" ou "desarmado", para "poderes manejá-lo", e, com isso, evitar os tumultos e garantir um estado harmonioso. Porém, o ordenador com esse propósito deve ter o cuidado de que as leis e ordenações ali instituídas evitem, sob todas as hipóteses, que a cidade se lance em expedientes de conquistas, visto que "o crescimento é o veneno de semelhantes repúblicas" (MAQUIAVEL, 2007a, p. 30). Essas conquistas, "se apoiadas numa república fraca [debole]", militarmente desestruturada, "são motivo de sua ruína" (MAQUIAVEL, 2007a, p. 31). Contudo, alerta Maquiavel, evitar que um estado cresça independe dos propósitos de um ordenador ou de ordenações. Repúblicas como Esparta e Veneza, determinadas a permanecer em breves termos, estão, na realidade, expostas às variações da fortuna, como comprovado pela história após a rebelião de Tebas, na primeira, e a batalha de Agnadello, na segunda.

${ }^{16}$ Sobre o modo como Maquiavel utiliza-se das atribuições de gênero em seu pensamento político, cf. o importante ensaio de Hanna Fenichel Pitkin, Fortune is a woman: gender \& politics in the thought of Niccolò Machiavelli (Chicago/London: The University of Chicago Press, 1999). Sobre o uso do adjetivo "efeminado", cf. em especial o Capítulo 5, “...because of women”, p. 109-137.

${ }^{17}$ No Capítulo XV de O Príncipe, ao considerar as qualidades reprováveis ou louváveis de um príncipe, vemos que, enquanto um é visto como "efeminado e pusilânime", outro é considerado "feroz e corajoso" (MAQUIAVEL, 1998, p. 74, grifo nosso). No Capítulo 46 do Livro III dos Discursos, por sua vez, lemos que "parece que entre uma cidade e outra certos modos e instituições diferem, criando homens mais duros ou mais efeminados" (MAQUIAVEL, 2007a, p. 450, grifo nosso). 
Ressurge a imagem da linha de sucessão na origem romana - a pouco citada -, em que o comportamento belicoso de Anco revelou-se indispensável, uma vez que foi capaz que "ripigliassero la virtù di Romulo", pois, de outra forma, "quella città sarebbe diventata effeminata, e preda de' suoi vicini" (MAQUIAVEL, 2007a, p. 77). Quando consideramos o modo de organização das guerras e o procedimento político dos romanos, vemos, destaca o Secretário, que à "fortuna" da República "se uniram a virtù e grande prudência". Pois, "se um príncipe" e um "povo" angariam "tanta reputação", os “outros príncipes e povos dos arredores terão medo de atacá-lo", respeitando-o. Disso resulta que, "nenhum deles o atacará, a não ser por necessidade". Nisso, "é como se só a tal poderoso coubesse escolher com qual de seus vizinhos quer travar guerra, aquietando os outros com a sua habilidade" (MAQUIAVEL, 2007a, p. 183-184). Não ser considerado como "efeminado", como atesta o exemplo dos latinos, tem um efeito de dissuasão sobre as potências rivais e circunvizinhas.

Por outro lado, uma cidade dividida é aquela que, sem um inimigo em comum para congregar a coletividade dos indivíduos perante uma causa compartilhada, desperta a potencialidade de uma guerra civil. A divisão do tecido social em facções apresenta um aspecto implicitamente danoso. Como o caso de Florença, do qual Maquiavel era testemunha ocular, onde as calúnias entre os indivíduos haviam motivado o "ódio", a divisão, as facções e a ruína (MAQUIAVEL, 2007a, p. 39). Essas divisões, que marcavam a historiografia florentina, como o próprio Secretário reconhece no Proêmio de sua História de Florença, haviam sido a "origem de tantas mortes, tantos exílios, tantas destruições de famílias, como nunca ocorreu em nenhuma outra cidade que se tenha memória" (MAQUIAVEL, 2007b, p. 8-9).

Mais do que isso, um ataque externo opera como aglutinador para os indivíduos em fragmentação faccionária. Segundo afirma no Capítulo 25 do Livro II dos Discursos - que tem, como argumento central, a ideia de que "atacar uma cidade desunida, para ocupá-la tirando proveito de sua desunião é decisão errônea -, os veientes, habitantes de uma região na cercania de Roma, "acreditaram que, atacando os romanos desunidos", poderiam vencê-los. Porém, “o ataque foi a razão da união destes e da ruína daqueles". "Porque", explica, "o motivo da desunião das repúblicas, no mais das vezes, são o ócio e a paz; e a razão da união são o medo e a guerra" (MAQUIAVEL, 2007a, p. 278, grifo nosso). Enquanto a ausência dos conflitos externos estimula as desavenças civis, que 
encontram seu desfecho na violência entre concidadãos, a ameaça externa garante certa "coesão"18.

Em resumo, o estado ocioso, militarmente inerte, é transformado em um organismo político vil, de pouca significância aos olhos das demais potências, ou discorde, onde alastram-se as facções. Em outras palavras, como propõe em nota Giorgio Inglese (2015, p. 210, nota 35, tradução nossa), ou belicosidade se extingue ou é pervertida em luta intestina. Perante uma "menor necessidade de lutar para sobreviver", isto é, de firmar-se contra inimigos externos, "o ócio prova o enfraquecimento e a corrupção" internamente.

\section{Considerações finais}

Diante desse percurso analítico, qual seriam, afinal, as implicações e as repercussões que essa forma de compreender a paz exercem no pensamento políticomilitar maquiaveliano?

Em primeiro lugar, e de modo mais imediato, essa noção sofre, nas teses do Secretário, um importante deslocamento semântico. Agora, a paz não pode ser concebida enquanto antitese da guerra, como situação de total negação para a existência de conflitos armados. Guerra e paz, nesse sentido, em Maquiavel, deixam de ser termos que excluem um ao outro (onde ou há guerra ou há paz). Antes disso, a predisposição para a guerra se transforma na condição de possibilidade para uma circunstância pacífica, mesmo que transitória (onde há paz porque há uma preocupação ininterrupta

${ }^{18}$ A mesma relação entre desunião e ócio pode ser identificada, também, no final do Livro I de a Arte da Guerra. Fabrizio, principal personagem do diálogo, em resposta a Cosimo, interlocutor que interpelava acerca da possível "confusão, escândalo e desordem" que uma "multidão de armados" poderia causar em um território que houvesse concedido armas aos seus habitantes, respondia que "se o lugar onde são ordenados é tão imbele que entre seus homens não haja armas, e tão unido que não haja capitães, esse tipo de ordenação os tornará mais ferozes contra o estrangeiro, mas não os tornará de modo algum mais desunidos, porque os homens bem-ordenados temem as leis, armados ou desarmados [...]" (MAQUIAVEL, 2006, p. 37). Todavia, se o lugar onde "os ordenais for belicoso e desunido, essa ordenação só será motivo de união", porque “[...] por si mesmos já terão antes armas e capitães, mas tais armas serão inúteis para a guerra, e os comandantes serão alimentadores de escândalos. E essa ordenação dá-lhes armas úteis para a guerra e comandantes eliminadores de escândalos"; porque nessas terras, quando "alguém é ofendido, recorre ao comandante de sua facção particular, e este, para manter a reputação, incita-o à vingança, e não à paz" (MAQUIAVEL, 2006, p. 37). É justamente o contrário aquilo que realiza um "comandante público", porque este "elimina a ocasião para escândalos e dá-se ensejo à união": as províncias "unidas e menos aguerridas [unite $e$ effeminate] perdem covardia e mantêm a união"; as "desunidas e escandalosas unem-se, e a ferocidade que costumam empregar desordenadamente converte-se em utilidade pública" (MAQUIAVEL, 2006, p. 37). 
com as coisas da guerra. Portanto, a paz migra de um período antitético ou antinômico à guerra para seu estágio preparatório.

Em segundo lugar, estamos diante de uma controversa imagem sobre a paz que, em seu limite, apresenta uma dimensão corrosiva, seja, ao promover o ócio, por debilitar a notoriedade de um estado em um contexto político predatório, ou seja por facilitar a degeneração societária com o princípio da guerra civil. O pensamento político maquiaveliano, então, desnuda sua tendência para as expansões territoriais. Isso significa que suas teses sobre o governo se apoiam sobre a constatação de uma espécie de necessidade da conquista por meio de movimentos militares. A existência de inimigos externos ameniza a latência dos humores internos que, quando regulados de maneira precária pelas instituições, promovem o alvorecer da guerra civil. Para evitar que o conflito interno, de natureza violenta, dilacere o estado, a guerra surge como um elemento que congrega os indivíduos em torno da necessidade de combater pela própria sobrevivência $^{19}$. Nesse caso, os exércitos não podem agir apenas dentro de uma lógica militar defensiva. A agressão, o impulso de submissão de outros povos e cidades, deve fazer parte de suas operações, mesmo que o instrumento da expansão não seja utilizado permanentemente.

Em terceiro lugar, essa estrutura conceitual, que concebe a paz através dessa feição, se alinhará ao projeto político-militar maquiaveliano das milícias próprias tanto em sua dimensão teórica, conforme exposto em a Arte da Guerra, quanto em sua

${ }^{19}$ Devemos notar que essa leitura, que atesta a pertinência das conquistas, possui desdobramentos consideráveis em Maquiavel. Para escapar de tornar-se presa de uma potência rival ou para evitar que a inércia militar deteriorasse a dinâmica interna, a submissão da liberdade de outros povos era essencial. Porém, se retomamos a análise dos regimes republicanos, guiando nosso olhar por entre a história de Roma, nos aproximamos de uma importante aporia. De acordo com Gennaro Sasso (1980, p. 485, tradução nossa), o impulso militar romano, motivado por suas estruturas de governo republicanas e populares, tornou possível a expansão territorial. Mas, isso culminou na formação do império, que é uma forma política distinta e negadora da essência republicana. $O$ resultado das conquistas é a "destruição, a lenta consumação" e, assim, "a negação do "instrumento" político e constitucional que o havia tornado possível". Isto é, "liberdade torna possível a conquista; mas a conquista destrói a liberdade” (SASSO, 1980, p. 485-486). Também Marco Geuna (2005, p. 33-35, tradução nossa) interpreta o caminho da república em expansão atrelada ao império na esteira de Sasso. Para Geuna, Roma é a república que amplia, que estende ano após ano suas conquistas territoriais. Mas as conquistas territoriais, com suas exigências, colocam em movimento dinâmicas que conduzem ao fim do vivere libero, ao fim do regime republicano e ao advento do império. Maquiavel, nota, apesar de se deter sobre tais dinâmicas, não parece "advertir plenamente a contradição que está no coração de seu modelo político, a antinomia pela qual a república, levando à formação do império, está exposta a um inexorável destino de autodestruição" (GEUNA, 2005, p. 34$35)$. 
dimensão prática, quando o Secretário organiza a polêmica Ordenança em Florença ${ }^{20}$-, fundado na premissa de soldados que devotavam "dedicação parcial" aos interesses públicos. Diferente dos soldados mercenários ${ }^{21}$, uma das fontes das mazelas das cidades italianas, que faziam da guerra seu meio de subsistência e, justamente por isso, não podiam resignar-se à paz, essas tropas deveriam prestar serviço militar apenas em ocasiões específicas. Tal atribuição permite entrever que os movimentos implícitos às atividades armadas são intervalados. Em tempos de paz, os soldados cidadãos suspenderiam suas atribuições militares, para, assim, retornar às suas atividades civis quotidianas $^{22}$. O uso dessas tropas condiz com a proposta da fuga da ociosidade militar: ao invés de as armas serem utilizadas em guerras internas, são direcionadas para um inimigo externo. A ordenação desse aparato cumpre, enfim, uma dupla função, embaraçando a imagem de debilidade do estado, que seria alvo fácil para qualquer dominação, e evitando os confrontos civis, que dilaceram as instituições políticas.

\section{Referências bibliográficas}

ANGLO, S. Machiavelli as a military authority. Some early sources. In: DENLEY, P.; ELAM, C. (Ed.). Florence and Italy: Renaissance studies in honour of Nicolai Rubistein. London: Westfield College, 1988, p. 321-334.

CICERONE, M. T.. Le Filippiche. In: Le Orazioni. Vol. IV. A cura di Giovanni Bellardi. Torino: UTET, 1978.

FOURNEL, J. L.; ZANCARINI, J. C. Guerra e Pace. In: SASSO, G. (Ed.). Machiavelli: Enciclopedia Machiavelliana. Vol. I. Roma: Istituto della Enciclopedia Italiana, 2014, p. 674-679.

FROSINI, Fabio. Guerra e Politica: considerazioni su alcuni testi di Machiavelli. Università di Urbino - IESA, 2004. Disponível em: < http://digital.csic.es/bitstream/10261/2093/1/17-04.pdf>. Acesso em 06/01/2020.

\footnotetext{
20 Sobre a atividade de Maquiavel nessa operação, cf. GUIDI, Andrea. Un segretario militante: politica, diplomazia e armi nel Cancelliere Machiavelli. Bologna: Il Mulino, 2009.

21 Acerca da interpretação que o Secretário faz da ação dos mercenários, cf. o capítulo XII d'O Príncipe e o capítulo 43 do Livro I dos Discursos.

${ }^{22}$ Conforme afirma em a Arte da Guerra, “devem os reis, se quiserem viver seguros, ter suas infantarias compostas de homens que, chegando o tempo de fazer guerra, a façam de bom grado, por amor ao rei, e, chegada a paz, com mais gosto retornem ao lar". Ao obter o "estado de paz", a militarização estatal resume-se aos exercícios periódicos de treinamento, pois nesse caso, "o rei deve querer que, chegada a paz, os príncipes voltem a governar seus povos, os gentis homens voltem ao cultivo de suas propriedades, e os infantes voltem a sua arte particular". Isto posto, "todos eles farão a guerra para ter paz, e não procurarão perturbar a paz para ter guerra” (MAQUIAVEL, 2006, p. 18).
} 
GEUNA, M. Machiavelli ed il ruolo dei conflitti nella vita politica. In: ARIENZO, A.; CARUSO, D. (Ed.). Conflitti. Napoli: Libreria Dante \& Descartes, 2005. p. 19-57.

GILBERT, F. Machiavelli e il suo tempo. Trad. di Alda de Caprariis e Gustavo Gozzi. Bologna: Il Mulino, 1977.

. Machiavelli: The Renaissance of The Art of War. In: PARET, P. Makers of Modern Strategy: From Machiavelli to the Nuclear Age. New York: Oxford University Press, 1986, p. 11-31.

INGLESE, G. Premessa al testo e note. In: MACHIAVELLI, Niccolò. Discorsi sopra la prima deca di Tito Livio. $10^{\mathrm{a}}$ ed. A cura di Giorgio Inglese. Milano: BUR Classici, 2015.

MACHIAVELLI, N. Opere I. A cura di Corrado Vivanti. Torino: Einaudi-Gallimard, 1997.

. Opere II. A cura di Corrado Vivanti. Torino: Einaudi-Gallimard, 1999.

MAQUiAVEL, N. A Arte da Guerra. Trad. de MF. São Paulo: Martins Fontes, 2006.

. Discursos sobre a primeira década de Tito Lívio. Trad. de MF. São Paulo: Martins Fontes, 2007a. . História de Florença. Trad. de MF. São Paulo: Martins Fontes, 2007b.

1998. . O Príncipe. $2^{\mathrm{a}}$ ed. Trad. de Maria Júlia Goldwasser. São Paulo: Martins Fontes,

MARCHAND, J. J. Niccolò Machiavelli: I primi scritti politici (1499-1512). Padova: Antenore, 1975.

NEPOTE, C. Opere. A cura di Leopoldo Agnes. Torino: UTET, 1977.

SASSO, G. Niccolò Machiavelli: storia del suo pensiero politico. Bologna: Il Mulino, 1980.

VEGEZIO, F. R. L'Arte Militare. Trad. di Antonio Angelini. Roma: Stato Maggiore dell'Esercito Ufficio Storico, 1984.

ZANZI, L. Machiavelli e gli "Svizzeri": e altre "machiavellerie" filosofiche concernenti la natura, la guerra, lo stato, a società, l'etica e la civiltà. Bellinzona: Edizioni Casagrande, 2009. 